Canadian

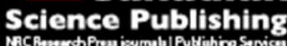

Applied Physiology, Nutrition, and Metabolism Physiologie appliquée, nutrition et métabolisme

\title{
Objectively Measured Physical Activity of Young Canadian Children Using Accelerometry
}

\begin{tabular}{|r|l|}
\hline Journal: & Applied Physiology, Nutrition, and Metabolism \\
\hline Manuscript ID & apnm-2015-0164.R1 \\
\hline Manuscript Type: & Article \\
\hline Complete List of Authors: & $\begin{array}{l}\text { Borkhoff, Cornelia; The Hospital for Sick Children, Child Health Evaluative } \\
\text { Sciences; Women's College Hospital, Women's College Research Institute; } \\
\text { University of Toronto, Institute of Health Policy, Management and } \\
\text { Evaluation } \\
\text { Heale, Liane; The Hospital for Sick Children, Pediatric Medicine } \\
\text { Anderson, Laura; The Hospital for Sick Children, Child Health Evaluative } \\
\text { Sciences } \\
\text { Tremblay, Mark; Children's Hospital of Eastern Ontario Research Institute, } \\
\text { The Healthy Active Living and Obesity Research Group (HALO) } \\
\text { Maguire, Jonathon; St. Michael's Hospital, Applied Health Research Centre, } \\
\text { Li Ka Shing Knowledge Institute } \\
\text { Parkin, Patricia; The Hospital for Sick Children, Pediatric Medicine } \\
\text { Birken, Catherine; Hospital for Sick Children, Pediatrics, University of } \\
\text { Toronto }\end{array}$ \\
\hline Keyword: & \begin{tabular}{l} 
pediatrics, physical activity < exercise \\
\hline
\end{tabular} \\
\hline
\end{tabular}




\section{Objectively Measured Physical Activity of Young Canadian Children Using Accelerometry}

Cornelia M. Borkhoff, $\mathrm{PhD}^{1,2,3,4}$, Liane D. Heale, $\mathrm{MD}^{5}$, Laura N. Anderson, $\mathrm{PhD}^{1,6}$, Mark S. Tremblay, $\mathrm{PhD}^{7,8}$, Jonathon L. Maguire, MD, MSc, FRCPC ${ }^{1,2,3,5,6,9}$ Patricia C. Parkin MD, FRCPC ${ }^{1,2,3,5}$, Catherine S. Birken, MD, MSc, FRCPC ${ }^{1,2,3,5,9}$, on behalf of the TARGet Kids! Collaboration*

*TARGet Kids! Collaboration - Co-Leads: Patricia C. Parkin, Catherine S. Birken, Jonathon L. Maguire; Scientific Advisory: Colin Macarthur, Muhammad Mamdani; Scientific Committee: Kawsari Abdullah, Laura N. Anderson, Imaan Bayoumi, Catherine S. Birken, Cornelia M. Borkhoff, Sarah Carsley, Yang Chen, Mikael Katz-Lavigne, Kanthi Kavikondala, Christine Koroshegyi, Christine Kowal, Grace Jieun Lee, Jonathon L. Maguire, Dalah Mason, Jessica Omand, Patricia C. Parkin, Navindra Persaud, Meta van den Heuvel, Peter Wong, Weeda Zabih; Site Investigators: Jillian Baker, Tony Barozzino, Joey Bonifacio, Douglas Campbell, Sohail Cheema, Brian Chisamore, Karoon Danayan, Paul Das, Mary Beth Derocher, Anh Do, Michael Dorey, Sloane Freeman, Keewai Fung, Charlie Guiang, Curtis Handford, Hailey Hatch, Sheila Jacobson, Tara Kiran, Holly Knowles, Bruce Kwok, Sheila Lakhoo, Margarita Lam-Antoniades, Eddy Lau, Fok-Han Leung, Jennifer Loo, Sarah Mahmoud, Rosemary Moodie, Julia Morinis, Sharon Naymark, Patricia Neelands, James Owen, Michael Peer, Marty Perlmutar, Navindra Persaud, Andrew Pinto, Michelle Porepa, Nasreen Ramji, Noor Ramji, Alana Rosenthal, Janet Saunderson, Rahul Saxena, Michael Sgro, Susan Shepherd, Barbara Smiltnieks, Carolyn Taylor, Thea Weisdors, Sheila Wijayasinghe, Peter Wong, Ethel Ying, Elizabeth Young.

\section{Affiliations:}

${ }^{1}$ Division of Pediatric Medicine and the Pediatric Outcomes Research Team (PORT), The Hospital for Sick Children, Toronto, ON, Canada; ${ }^{2}$ Child Health Evaluative Sciences, The Hospital for Sick Children Research Institute, Toronto, ON, Canada; ${ }^{3}$ Institute of Health Policy, Management and Evaluation, University of Toronto, Toronto, ON Canada; ${ }^{4}$ Women's College Research Institute, Women's College Hospital, Toronto, ON, Canada; ${ }^{5}$ Department of Pediatrics, Faculty of Medicine, University of Toronto, Toronto, ON, Canada; ${ }^{6}$ Applied Health Research Centre, Li Ka Shing Knowledge Institute, St. Michael's Hospital, Toronto, ON, Canada; ${ }^{7}$ Children's Hospital of Eastern Ontario Research Institute, Ottawa, ON;

${ }^{8}$ Department of Pediatrics, Faculty of Medicine, University of Ottawa, Ottawa, ON;

${ }^{9}$ Department of Pediatrics, St. Michael's Hospital, Toronto, ON, Canada

Corresponding Author: Cornelia M. Borkhoff, PhD, Child Health Evaluative Sciences, The Hospital for Sick Children, Room 10.9832, $10^{\text {th }}$ Floor - Peter Gilgan Centre for Research and Learning, 686 Bay Street, Toronto, ON M5G 0A4 Canada; Tel: 416-813-7654 X309735; Fax: 416-813-5663; E-mail: cory.borkhoff@sickkids.ca

Short Title: Accelerometry in Young Children

Word count (excluding abstract, tables, figures and references): 3721

Abbreviations: CHMS - Canadian Health Measures Survey; LPA - light physical activity; MVPA: moderate-to-vigorous physical activity; PA - physical activity. 


\section{Addresses and e-mail addresses of co-authors:}

Liane D. Heale, MD *co-first author

Division of Pediatric Medicine, Department of Pediatrics

The Hospital for Sick Children

686 Bay Street

Toronto, ON M5G 0A4 Canada

E-mail: liane.heale@,sickkids.ca

Laura N. Anderson, PhD

Child Health Evaluative Sciences

The Hospital for Sick Children

Room 10.9832, $10^{\text {th }}$ Floor - Peter Gilgan Centre for Research and Learning 686 Bay Street

Toronto, ON M5G 0A4 Canada

E-mail: laura.anderson@sickkids.ca

Mark S. Tremblay, $\mathrm{PhD}$

The Healthy Active Living and Obesity Research Group (HALO)

Children's Hospital of Eastern Ontario Research Institute

401 Smyth Rd

Ottawa, ON K1H 8L1 Canada

E-mail: $\underline{\text { mtremblay@,cheo.on.ca }}$

Jonathon L. Maguire, MD, MSc, FRCPC

Applied Health Research Centre, Li Ka Shing Knowledge Institute

St. Michael's Hospital

30 Bond St.

Toronto, ON M5B 1W8 Canada

E-mail: jonathon.maguire@utoronto.ca

Patricia C. Parkin MD, FRCPC

Division of Pediatric Medicine, Department of Pediatrics

The Hospital for Sick Children

Room 10.9708, $10^{\text {th }}$ Floor - Peter Gilgan Centre for Research and Learning 686 Bay Street

Toronto, ON M5G 0A4 Canada

E-mail: patricia.parkin@sickkids.ca

Catherine S. Birken, MD, MSc, FRCPC

Division of Pediatric Medicine, Department of Pediatrics

The Hospital for Sick Children

Room 10.9708, $10^{\text {th }}$ Floor - Peter Gilgan Centre for Research and Learning 686 Bay Street

Toronto, ON M5G 0A4 Canada

E-mail: catherine.birken@sickkids.ca 


\begin{abstract}
Objectives: To describe objectively measured physical activity (PA) and sedentary time of infants, toddlers, and preschoolers and determine the proportion meeting Canadian agespecific physical activity guidelines.
\end{abstract}

Methods: Ninety children (47 girls, 43 boys; mean age 32 (range, 4-70) months)

attending scheduled health supervision visits and in the TARGet Kids! cohort wore an Actical accelerometer for 7 days. Participants with 4 or more valid days were included in the analysis. Time, in mean minutes per day ( $\mathrm{min} / \mathrm{d})$, spent sedentary, and in light physical activity (LPA), moderate-to-vigorous physical activity (MVPA) and total PA was determined using published cut-points; age groups were compared using ANOVA.

Results: Twenty-three percent of children $<18$ months $(n=28)$ and $76 \%$ of children $18-59$ months $(n=45)$ met the guideline of $180 \mathrm{~min} / \mathrm{d}$ of total PA; $13 \%$ of children $\geq 60$ months $(n=$ 17) met the guideline of $60 \mathrm{~min} / \mathrm{d}$ of MVPA. Children $<18$ months spent more of their waking time per day engaged in sedentary behaviours ( $79 \% ; \sim 7.3$ hours) compared to children $18-59$ months (63\%; 6.6 hours) and children $\geq 60$ months $(58 \% ; \sim 6.6$ hours).

Conclusions: Most children aged $18-59$ months met the Canadian physical activity guidelines for children 0-4 years, whereas few younger than 18 months met the same guidelines. Only $13 \%$ of children $\geq 5$ years met their age-specific physical activity guidelines. Further research is needed to develop, test and implement effective strategies to promote physical activity and reduce sedentary behaviour in very young children.

\title{
Word count: 250
}

Key Words: physical activity, accelerometer, infant, toddler, preschool, guidelines 


\section{Introduction}

Increased physical activity in early childhood is associated with improvements in bone health, psychosocial health, cardiometabolic health, adiposity and cognitive and motor skill development (Timmons et al. 2012).

National organizations have attempted to translate the research on health benefits into specific activity guidelines. The National Association for Sport and Physical Education from the United States recommends at least one hour of structured and one or more hours of unstructured physical activity every day for children from birth to age 59 months (American Alliance for Health, Physical Education, Recreation and Dance 2002). Canadian and Australian guidelines recommend that children aged 0-59 months accumulate 180 minutes per day (min/d) of physical activity at any level of intensity (Australian Government, The Department of Health 2009; Tremblay et al. 2012a). The Canadian guidelines also recommend a progression towards $60 \mathrm{~min} / \mathrm{d}$ of more energetic play by 60 months of age to align with the $60 \mathrm{~min} / \mathrm{d}$ of moderate-to-vigorous physical activity (MVPA) recommendation for the 5-17 year age group (Tremblay et al. 2011a). Age-specific physical activity guidelines provide clinicians with a framework for making specific activity recommendations and allow researchers to compare physical activity levels against a standard.

Direct measurement of physical activity using valid instruments can be used to assess adherence with these guidelines and to provide health care professionals and governmental bodies with information to guide interventions and policies for this age group. Accelerometers are activity monitors that measure motion in multiple dimensions and provide valid objective estimates of intensity, duration, and frequency of physical activity (Hnatiuk et al. 2012; Oliver et al. 2007). Accelerometers can provide objective estimates of the amount of time children usually spend sedentary and in light physical activity (LPA) and MVPA. Accelerometer measurements are valid, reliable and feasible for quantifying physical activity at all intensities 
in preschool-aged children (i.e., ages 36 - 59 months) (Adolph et al. 2012; Cliff et al. 2009; Pate et al. 2006; Pfeiffer et al. 2006). In studies assessing the validity of accelerometers in children less than 36 months of age, two demonstrated that accelerometers can accurately distinguish sedentary time from LPA in this age group (Costa et al. 2014; Van Cauwenberghe 2011), and another demonstrated valid estimates of MVPA when compared with direct observation of physical activity (Trost et al. 2012).

The majority of the accelerometer-based physical activity studies in young children have focused on preschool children (Hnatiuk et al. 2014). These studies reported considerable variability in total time spent in physical activity at all intensities and the proportion of children meeting physical activity guidelines (ranging from 5 to 99.5\%) (Beets et al. 2011; Colley et al. 2013; Hinkley et al 2012; Hnatiuk et al. 2014). These large discrepancies, partially explained by differences in devices used to measure physical activity, cut-points assigned to LPA and MVPA, and guidelines employed, make it difficult to accurately describe physical activity levels of preschool children (Hnatiuk et al. 2014).

To the best of our knowledge, there are only two published studies that objectively measured physical activity levels in children less than 36 months of age, neither of which included Canadian children; the results are also inconsistent (Hnatiuk et al. 2012; Wijtzes et al. 2013). Thus, the aim of this study was to describe objectively measured physical activity and sedentary time of a Canadian sample of infants, toddlers, and preschoolers and assess their adherence with the recently published physical activity guidelines for their corresponding age groups (Tremblay et al. 2011a; Tremblay et al. 2012a). 


\section{Materials and methods}

\section{Study design}

This was a cross-sectional study of healthy children who attended scheduled health supervision visits at a TARGet Kids! participating pediatric or family medicine primary care practice in Toronto, Canada between January, 2013 and April, 2014.

\section{Study population and recruitment}

TARGet Kids! (The Applied Research Group for Kids) is a primary care practice-based research network in Toronto, Canada. It was created to examine growth and developmental trajectories of infants, toddlers and preschool-aged children (Carsley et al. 2014). Trained research personnel at two primary care practices approached parents of healthy children less than 6 years of age to participate in our accelerometry study during regularly scheduled wellchild physician visits. Children with chronic condition(s) (except for asthma), health conditions affecting growth (e.g., cystic fibrosis), severe developmental delay, and children whose families were not able to complete questionnaires in English were excluded from the study. This study was granted ethics approval by The Hospital for Sick Children Research Ethics Board. All parents of participating children consented to participation in the study.

Parents completed questionnaires on sociodemographic information, health, and health related behaviours. Trained research personnel obtained height and weight, for each participant. Body mass index (BMI) was calculated as weight in kilograms divided by the height in meters squared. For growth status, centiles were assigned to each participant using the 2006 World Health Organization (WHO) Child Growth Standards (World Health Organization 2006). Centile was determined using weight-for-length for children under 2 years of age and BMI-for-age for children 2 years of age and older. Children aged 0 to 5 years were characterized as underweight if in the $<3^{\text {rd }}$ centile and overweight if in the $>97^{\text {th }}$ centile. Children 5 years and older were characterized as underweight if in the $<3^{\text {rd }}$ centile and 
overweight if in the $>85^{\text {th }}$ centile.

\section{Measurement of physical activity}

Parents were instructed to attach the ActicalTM accelerometer (Phillips - Respironics, Oregon, USA) over their right hip of their child with a Velcro belt, 24 hours/d for 7 consecutive days. While they are water resistant, accelerometers were removed during bathing or swimming as they are not waterproof. The ActicalTM (small size: $28 \times 27 \times 10 \mathrm{~mm}$; light weight: $17 \mathrm{~g}$ ) is an omnidirectional accelerometer most sensitive to movement in the vertical plane, capable of detecting both sedentary and high energy movements (sensitivity range: 0.5-3.0 Hz). While accelerometers were set to collect digitized values in 2 second epochs, the data were aggregated and analysed in a count value per minute (cpm). The Actical ${ }^{\mathrm{TM}}$ has been validated for use in preschool aged children (Adolph et al. 2012; Pfeiffer et al. 2006). Accelerometers were initialized to start collecting data at midnight following their physician visit. Parents returned the accelerometers to the TARGet Kids!-affiliated practice in a prepaid envelope.

\section{Statistical analysis}

The data were reduced using a SAS-based macro consistent with the Canadian Health Measures Survey (available at http://www.haloresearch.ca/accel/) (Colley et al. 2011; Colley et al. 2012b; Colley et al. 2013). Participants with 4 or more valid days were included in the analysis (Colley et al. 2011; Colley et al. 2012b; Colley et al. 2013). A valid day was defined by at least 5 hours of wear time (Pfeiffer et al. 2009). To minimize the impact of wear-time variation (Katapally and Muhajarine 2014) and to not overestimate sedentary time with sleep time, we defined wear time as waking hours between 8:00am and 8:00pm. Actual wear time was calculated by subtracting non-wear time from this 12-hour period. Non-wear time was defined by at least 60 minutes of consecutive movement counts of 0 , allowing for up to 2 minutes of movement counts between 0 and 100 (Colley et al. 2013).

To reduce measurement error from parental motion, the participants were divided into 
emerging ambulation $(<18$ months) and ambulatory $(\geq 18$ months) groups. We based our 18 month age threshold on the normal developmental milestone for gross motor that $95 \%$ of children can walk; it is considered a red flag if a child is not walking at 18 months (Council on Children With Disabilities and Bright Futures Steering Committee, 2006). We wished to characterize the physical activity of children in these 2 groups, recognizing that some of the movement detected in children $<18$ months may be parental motion.

The ambulatory group was subdivided into two groups to correspond with the Canadian physical activity guidelines (i.e., $18-59$ months; $\geq 60$ months). The $18-59$ month age group was further divided into 18-35 month and 36-59 month age groups to facilitate direct comparisons with results of previous studies (Colley et al. 2013; Hnatiuk et al. 2012; Wijtzes et al. 2013). Time spent at different levels of movement intensity was based on published cut-points. Sedentary behaviour was defined as all movement intensity less than $100 \mathrm{cpm}$ (Wong et al. 2011). LPA and MVPA were characterized by $100-1149$ and $\geq 1150$ cpm, respectively (Adolph et al. 2012; Wong et al. 2011). Total PA was the sum of LPA and MVPA.

The mean daily minutes spent sedentary, and in LPA, MVPA and total PA for all valid days were reported by age group and sex. Comparisons of time spent at different levels of movement intensity were made according to age group and sex using ANOVA with pairwise contrasts. To determine the proportion of children meeting age-specific physical activity guidelines, we used the analytical approach used in the CHMS analyses (Colley et al. 2011; Colley et al. 2012b; Colley et al. 2013). For children aged $0-59$ months, guideline adherence was defined as the probability of accumulating at least 180 minutes of daily physical activity at any intensity. For children $\geq 60$ months, guideline adherence was defined as the probability of accumulating at least 60 minutes of MVPA at least 6 days a week. Given that some children will not have at least 6 valid days of data, a Bayesian approach is utilized to 
incorporate information from individuals with 4 or more valid days to estimate an individual's probability of being active at least 6 out of 7 days. The proportion of children meeting the guidelines was the average of these individual probabilities. For further details, please see Colley et al. (2012b). Statistical significance was defined as $P<0.05$; all statistical tests were two-sided. All analyses were conducted using SAS Version 9.3. (SAS Institute Inc., Cary, NC, USA). 


\section{Results}

\section{Population}

In total, 117 children participated in this accelerometry study. Of these, 90 were included in the final analysis as 27 children did not have 4 valid days of wear time (Table 1). The mean age was 32 months (range, $4-70$ months), and 48\% were male. Maternal ethnicity was predominantly White European (59\%); for the remaining children, maternal ethnicity was Asian (14\%), Other (17\%), or missing (10\%). The majority of children $(83 \%)$ were at a normal weight. The average number of days that children wore the accelerometer was 6.1 (range, $4.0-7.0$ ) days.

\section{Average daily physical activity and sedentary time}

Children $<18$ months were significantly less active than children in the two older age groups $(p<0.001)$. On average, they accumulated 118 daily minutes of total PA and spent $79 \%(\sim 7.3$ hours) of their waking time per day engaged in sedentary behaviours, $21 \%$ ( $\sim 1.9$ hours) engaged in LPA and $<1 \%$ ( $\sim 4$ mins) of their day engaged in MVPA (Table 2$)$. On average, children 18 - 59 months accumulated 232 daily minutes of total PA and spent $63 \%(\sim 6.6$ hours) of their waking time per day engaged in sedentary behaviours, $32 \%$ ( $\sim 3.4$ hours) engaged in LPA and 5\% ( 29 mins) of their day engaged in MVPA. On average, children $\geq 60$ months accumulated 282 daily minutes of total PA and spent $58 \%$ ( $\sim 6.6$ hours $)$ of their waking time per day engaged in sedentary behaviours, 33\% ( $\sim 3.7$ hours) engaged in LPA and $9 \%$ ( $\sim 58$ mins) of their day engaged in MVPA. The average accelerometer wear time for all children in the sample was approximately 10.2 (range, $7.7-12.0$ ) hours per day. There were no significant differences in boys compared to girls in overall mean $(95 \% \mathrm{CI})$ daily minutes of sedentary time: $407(392-422)$ vs. $408(391-424)$; $\mathrm{p}=0.99$, LPA: $179(157-200)$ vs. 180 $(162-197) ; p=0.93$; or MVPA: $29(21-37)$ vs. 25 (17 - 33); $p=0.54$ for any age group. 


\section{Proportion meeting physical activity guidelines}

Twenty-three percent (95\% CI: $9.1-36.6)$ of children $<18$ months, and 76 percent $(95 \% \mathrm{CI}$ : $67.6-84.8$ ) of children $18-59$ months met the guideline of at least 180 minutes of physical activity at any intensity on at least 4 days per week (the operational definition of meeting the guideline of 180 minutes of total PA every day) (Figure 1). Thirteen percent (95\% CI: 1.2 24.1) of children $\geq 60$ months met the guideline of at least 60 minutes of MVPA on at least 6 days per week (the operational definition of meeting the guideline of 60 minutes of MVPA every day). 


\section{Discussion}

The majority of children aged 18 - 59 months in our study met the Canadian physical activity guidelines of at least 180 minutes of total physical activity every day, whereas only $13 \%$ of children 5 years and older met the recommended 60 minutes of daily MVPA. Our findings on children over the age of 3 years are in line with the adherence to physical activity guidelines reported by the 2009-2011 Canadian Health Measures Survey (Colley et al. 2013). To the best of our knowledge, this is the first Canadian study to objectively measure physical activity in children less than 3 years and the first study to use accelerometers to objectively measure crawling and non-ambulatory movement in children less than 18 months. We found that $23 \%$ of children less than 18 months met the guideline of 180 minutes of daily physical activity at any intensity. Because our results are consistent with CHMS data for the same age groups, we likely have a good estimate of minutes at varying levels of movement intensity for children less than 3 years. However, accelerometer cut-points used to define different levels of intensity can have an important impact on estimates of physical activity. The MVPA cut-point we used was developed for Actical ${ }^{\mathrm{TM}}$ accelerometer data collected in 3-5 year old children (Adolph et al. 2012). The sedentary cut-point we used was developed in adults (Wong et al. 2011) and may have underestimated the time spent in light physical activity, supporting the need for accelerometer count cut-points specifically for children less than 3 years of age. Had we used the sedentary cut-point identified by Adolph and colleagues (2012) of $25 \mathrm{cpm}$, we would have reported a higher average daily minutes of total physical activity in children less 3 years.

We report very low activity levels for children in the $<18$ month age group. Our sample included a large number of young infants (mean age of 9 months for this age group). While there are accelerometer validation studies in children less than 36 months of age (Costa et al. 2014; Van Cauwenberghe 2011), there are no validation studies involving children less 
than 12 months of age. Our presentation of physical activity in children less than 3 years is exploratory and therefore our results should be interpreted with caution. We recognize that some of the movement detected in children $<18$ months may be parental motion. In future studies of this age group, we recommend collecting data on ambulation and categorizing children into one of 3 categories (a. not crawling or walking; b. crawling or bum shuffling; c. walking). As we explore determinants of physical activity and sedentary time in infants, it may be useful to reconsider time-based recommendations for this age group. For example, physical activity guidelines in Australia encourage physical activity, focusing on supervised floor-based play in safe environments, for infants $<12$ months without specific time-based recommendation (Australian Government, The Department of Health 2009).

The majority of children aged 18-59 months appear to be meeting the Canadian physical activity guidelines with a guideline adherence rate of $76 \%$ and a mean total PA of $232 \mathrm{~min} / \mathrm{d}$. Our results for the proportion of children meeting the guidelines are consistent with the previously published national sample of children (Colley et al. 2013). In the national sample of 3-4 year olds, $84 \%$ met the guideline of at least 180 minutes of daily total PA; $84 \%$ of our children in the 3-4 year age group met the same standard (see Table 3). However, the mean total PA for our sample was more than $100 \mathrm{~min} / \mathrm{d}$ lower than those reported by Colley et al. (2013). Our 36-59 month age group accumulated $245 \mathrm{~min} / \mathrm{d}$ of total PA and $31 \%(\sim 3.4$ hours) of their day engaged in LPA and 7\% ( 43 mins) of their day engaged in MVPA versus $352 \mathrm{~min} / \mathrm{d}$ of total PA and $41 \%$ ( 4.8 hours) of their day engaged in LPA and $9 \%$ ( $\sim 66 \mathrm{mins})$ of their day engaged in MVPA reported by Colley et al. (2013). Both studies used the Actical $^{\mathrm{TM}}$ accelerometer with the same activity cut-points and definitions for a valid day of wear time, so it is unlikely that inconsistent methodologies account for the lower physical activity levels we report. One possible explanation is that our sample was limited to an urban population recruited from primary care. Another possible explanation is that it may reflect 
changes over time as our data were collected from 2013-2014 versus 2009-2011. However, both studies draw a similar conclusion - the majority of children aged 3-4 years are meeting the Canadian physical activity guidelines.

In contrast, our results are inconsistent with other studies that reported very low proportions of children meeting the guidelines for the same age group (Hinkley et al. 2012; Wijtzes et al. 2013). For example, Wijtzes et al. (2013) and Hinkley et al. (2012) reported that $0 \%$ and $5 \%$ of the children aged $18-59$ months in their studies met the guideline of $180 \mathrm{~min} / \mathrm{d}$ of total PA, respectively. The Actigraph ${ }^{\mathrm{TM}}$ accelerometer was used in these studies with an LPA cut-point of $1208 \mathrm{cpm}$, which may have underestimated total PA. Studies have demonstrated that an LPA cut-point of approximately $100 \mathrm{cpm}$ for the Actigraph ${ }^{\mathrm{TM}}$ is better at distinguishing LPA from sedentary time (Janssen et al. 2013; Van Cauwenberghe et al. 2011). When these lower cut-points were adopted in other studies using the Actigraph ${ }^{\mathrm{TM}}$, the proportion of children meeting guidelines is similar to what we have reported (Hnatiuk et al. 2012; Obeid et al. 2011). While supporting that the majority of children in the 18-59 month age group meet the guidelines when appropriate cut-points are used, these results emphasize the importance of establishing a standard methodology using the best evidence for ageappropriate cut-points.

The average daily minutes of MVPA and proportion of children meeting the physical activity guidelines for the $\geq 60$ months age group in our sample were similar to those reported by Colley et al. (2013). Children in our sample averaged $10 \mathrm{~min} / \mathrm{d}$ less MVPA than those reported in the CHMS study (see Table 3) (Colley et al. 2013), though, like the CHMS, they spent $9 \%$ of their day engaged in MVPA. However, because they spent a greater percentage of their day engaged in sedentary behaviours and a lower percentage of their day engaged in LPA, this suggests that the children in our study were somewhat less active than a previously published national sample of children (Colley et al. 2013). 
The apparent decline in physical activity adherence after age 5 is partly due to the changes in physical activity guidelines when children transition from $0-4$ years to the 5-17 year age group, rather than a decrease in activity level. In our sample, there was a trend towards increased LPA and MVPA for children in the $\geq 60$-month age group compared to the 18-59 month group, despite a large decline in the proportion meeting guidelines. A similar increase in physical activity was found with increasing age within the 18-59 month age group, with the older group more active and with more MVPA than the younger group. However, while the majority of children in the 18-59 month age group met the physical activity guidelines, the large majority of that time was spent in LPA, as demonstrated in other studies (Colley et al. 2013; Hnatiuk et al. 2014). Thus, many children aged 18-59 months are not progressing towards 60 minutes of MVPA; this may explain why only $13 \%$ of children $\geq 60$ months met their age-specific guidelines.

Canadian sedentary behaviour guidelines do not specify a total daily sedentary time target. Rather, guidelines only specify time restrictions on screen time: that children under age 2 do not engage in screen time (American Academy of Pediatrics Committee on Public Education 2001), and screen time be limited to less than 1 hour per day in 3 to 4 year old children (Tremblay et al. 2012b), and to no more than 2 hours per day in 5 year old children (Tremblay et al. 2011b), While our data show that children aged $<18$ months, $18-59$ months and $\geq 60$ months spend $79 \%$ ( $\sim 7.3$ hours), $63 \%$ ( $\sim 6.6$ hours), $58 \%$ ( $\sim 6.6$ hours) of their day, respectively, engaged in sedentary behaviours, we do not know how much of that time was screen time. A higher proportion of waking hours was spent in sedentary time, particularly for the two youngest age groups, when compared with CHMS data (Colley et al. 2013). What specific behaviours the youngest children are engaging in during sedentary time may be best explored using parent-report or direct observation (Colley et al. 2012). 
Study limitations include using the Actical ${ }^{\mathrm{TM}}$ model of accelerometer. While its use in the preschool age group is supported by the literature (Adolph et al. 2012; Cliff et al. 2009; Pfeiffer et al. 2006), no studies have validated the Actical ${ }^{\mathrm{TM}}$ accelerometer for children aged $<$ 36 months. In addition, the cut-point used to distinguish sedentary time from LPA was derived from data validated in adults (Wong et al. 2011). We chose this cut-point to allow a direct comparison with the results from the national sample (Colley et al. 2013), but appreciate that the validity of our results could be strengthened by age-specific cut-points. Despite this limitation, our results are consistent with previous studies that used similar cutpoints validated in young children for the Actigraph ${ }^{\mathrm{TM}}$ accelerometer (Hnatiuk et al. 2012; Obeid et al. 2011). Further, Straker and Campbell (2012) created translation equations to compare the Actigraph ${ }^{\mathrm{TM}}$ and Actical ${ }^{\mathrm{TM}}$ accelerometer and our LPA cut-point aligns with the cut-point range that has been validated for the Actigraph ${ }^{\mathrm{TM}}$ in toddlers and preschool children (Janssen et al. 2013; Pate et al. 2006; Trost et al. 2012; Van Cauwenberghe et al. 2011 ). We also acknowledge that with the ActicalTM not being waterproof and removed during swimming, we may have underestimated physical activity. In addition, seasonal variation could not be assessed in our sample nor could differences in physical activity and sedentary time between normal weight and overweight children because of sample size; both are areas of future research. Finally, we acknowledge the limitation of a cross-sectional design and recognize that longitudinal studies are needed to better understand physical activity trajectories of children from an early age.

\section{Conclusions}

The majority of children aged $18-59$ months in our study met the Canadian physical activity guidelines for children 0-4 years, whereas few younger than 18 months met the same guidelines. Despite a trend towards increasing MVPA in the older age groups, only $13 \%$ of 
children $\geq 60$ months of age met the guidelines of 60 min of daily MVPA. While children under 18 months appeared relatively inactive, further research is needed to validate accelerometer-based physical activity measurement and develop accelerometer count cutpoints in this age group. This will aid in the development of effective strategies to promote physical activity and reduce sedentary behaviours in very young children. 


\section{Acknowledgements}

We would like to thank all of the participating families for their time and involvement in TARGet Kids! and are grateful to all practitioners who are currently involved in the TARGet Kids! research network. Steering Committee: Tony Barozzino, Brian Chisamore, Mark Feldman and Moshe Ipp. Research Team: Kathleen Abreo, Dharma Dalwadi, Tarandeep Malhi, Antoinetta Pugliese, Megan Smith, Laurie Thompson. Applied Health Research Centre: Christopher Allen, Yang Chen, Hannah Chung, Gerald Lebovic, Magda Melo. Mount Sinai Services Central Laboratory: Azar Azad. 
Funding Source: Funding of the TARGet Kids! research network was provided by the Canadian Institutes for Health Research (CIHR) Institute of Human Development, Child and Youth Health, the CIHR Institute of Nutrition, Metabolism and Diabetes, and the St. Michael's Hospital Foundation. The Pediatric Outcomes Research Team is supported by a grant from The Hospital for Sick Children Foundation. The funding agencies had no role in the design and conduct of the study, the collection, management, analyses and interpretation of the data, or the preparation, review and approval of the manuscript.

Financial Disclosure: The authors have no financial relationships relevant to this article to disclose.

Conflict of Interest: The authors have no conflict of interest to disclose.

\section{Authors' contributions}

Cornelia M. Borkhoff: Dr. Borkhoff participated in study conception and design, carried out the analyses, revised and finalized the manuscript, and approved the final manuscript.

Liane D. Heale: Dr. Heale participated in data analysis and interpretation, wrote the first draft of the manuscript, and approved the final manuscript. Dr. Liane Heale is the person who wrote the first draft of the manuscript; we would ask that she be acknowledged as the co-first author. No honorarium, grant, or other form of payment was given to anyone to produce the manuscript.

Laura N. Anderson: Dr. Anderson coordinated and supervised data collection, critically reviewed the manuscript, and approved the final manuscript.

Mark S. Tremblay: Dr. Tremblay participated in data interpretation, critically reviewed the manuscript, and approved the final manuscript.

Jonathon L. Maguire: Dr. Maguire designed the data collection instruments, coordinated and supervised data collection, critically reviewed the manuscript, and approved the final manuscript.

Patricia C. Parkin: Dr. Parkin designed the data collection instruments, coordinated and supervised data collection, critically reviewed the manuscript, and approved the final manuscript as submitted.

Catherine S. Birken: Dr. Birken participated in study conception, designed the data collection instruments, coordinated and supervised data collection, critically reviewed the manuscript, and approved the final manuscript as submitted.

All authors agree to be accountable for all aspects of the work in ensuring that questions related to the accuracy or integrity of any part of the work are appropriately investigated and resolved. 


\section{References}

Adolph, A.L., Puyau, M.R., Vohra, F.A., Nicklas, T.A., Zakeri, I.F., Butte, N.F. 2012.

Validation of uniaxial and triaxial accelerometers for the assessment of physical activity in preschool children. J Phys Act Health 9(7): 944-953.

American Academy of Pediatrics Committee on Public Education. 2001. Children, adolescents, and television. Pediatrics 107(2): 423-426.

American Alliance for Health, Physical Education, Recreation and Dance (AAHPERD). 2002. NASPE releases first ever physical activity guidelines for infants and toddlers. Illinois $\mathbf{J}$ Health Physical Education Recreation Dance 50: 31-32.

Australian Government. The Department of Health. 2009. Get up and grow: Healthy eating and physical activity for early childhood. Available from:

http://www.health.gov.au/internet/main/publishing.nsf/Content/phd-early-childhood-nutritionresources Accessed: January 15, 2015.

Beets, M.W., Bornstein, D., Dowda, M., Pate, R.R. 2011. Compliance with national guidelines for physical activity in U.S. preschoolers: Measurement and interpretation. Pediatrics 127(4): 658-664.

Carsley, S., Borkhoff, C.M., Maguire, J.L., Birken, C.S., Khovratovich, M., McCrindle, B., et al. 2015. Cohort profile: The applied research group for kids (TARGet Kids!). Int J Epidemiol 44(3): 776-788.

Cliff, D.P., Reilly, J.J., Okely, A.D. 2009. Methodological considerations in using accelerometers to assess habitual physical activity in children aged 0-5 years. J Sci Med Sport 12(5): 557-567.

Colley, R.C., Gorber, S.C., Tremblay, M.S. 2010. Quality control and data reduction procedures for accelerometry-derived measures of physical activity. Health Rep 21: 63-69. 
Colley, R.C., Garriguet, D., Janssen, I., Craig, C.L., Clarke, J., Tremblay, M.S. 2011. Physical activity of Canadian children and youth: Accelerometer results from the 2007 to 2009

Canadian Health Measures Survey. Health Rep 22: 15-23.

Colley, R.C., Wong, S.L., Garriguet, D., Janssen, I., Connor Gorber, S., Tremblay, M.S. 2012a. Physical activity, sedentary behavior and sleep in Canadian children: a comparison between parent-report and accelerometry measures and their relative association with health outcomes. Health Rep 23: 1-9.

Colley, R.C. 2012b. Actical Accelerometer Data Analysis Support Tool: Harmonizing with the Canadian Health Measures Survey $($ Accel +). Available at: www.haloresearch.ca/accel. Accessed: January 15, 2015.

Colley, R.C., Garriguet, D., Adamo, K.B., Carson, V., Janssen, I., Timmons, B.W., et al. 2013. Physical activity and sedentary behavior during the early years in Canada: A crosssectional study. Int J Behav Nutr Phys Act 10:54.

Costa, S., Barber, S.E., Cameron, N., Clemes, S.A. 2014. Calibration and validation of the ActiGraph GT3X+ in 2-3 year olds. J Sci Med Sport 17(6): 617-622.

Hinkley, T., Salmon, J., Okely, A.D., Crawford, D., Hesketh, K. 2012. Preschoolers' physical activity, screen time, and compliance with recommendations. Med Sci Sports Exerc 44(3): $458-465$.

Council on Children With Disabilities; Section on Developmental Behavioral Pediatrics; Bright Futures Steering Committee; Medical Home Initiatives for Children With Special Needs Project Advisory Committee. 2006. Identifying infants and young children with developmental disorders in the medical home: An algorithm for developmental surveillance and screening. Pediatrics 118: 405-20. 
Hnatiuk, J., Ridgers, N.D., Salmon, J., Campbell, K., McCallum, Z., Hesketh, K. 2012. Physical activity levels and patterns of 19-month-old children. Med Sci Sports Exerc 44(9): 1715-1720.

Hnatiuk, J.A., Salmon, J., Hinkley, T., Okely, A.D., Trost, S. 2014. A review of preschool children's physical activity and sedentary time using objective measures. Am J Prev Med 47(4): 487-497.

Janssen, X., Cliff, D.P., Reilly, J.J., Hinkley, T., Jones, R.A., Batterham, M., et al. 2013.

Predictive validity and classification accuracy of ActiGraph energy expenditure equations and cut-points in young children. PLoS One 8(11): e79124.

Katapally, T.R., Muhajarine, N. 2014. Towards uniform accelerometry analysis: A standardization methodology to minimize measurement bias due to systematic accelerometer wear-time variation. J Sports Sci Med 13: 379-386.

Obeid, J., Nguyen, T., Gabel, L., Timmons, B.W. 2011. Physical activity in Ontario preschoolers: Prevalence and measurement issues. Appl Physiol Nutr Metab 36(2): 291-297.

Oliver, M., Schofield, G.M., Kolt, G.S. 2007. Physical activity in preschoolers: Understanding prevalence and measurement issues. Sports Med 37(12): 1045-1070.

Pate, R.R., Almeida, M.J., McIver, K.L., Pfeiffer, K.A., Dowda, M. 2006. Validation and calibration of an accelerometer in preschool children. Obesity 14(11): 2000-2006.

Pfeiffer, K.A., McIver, K.L., Dowda, M., Almeida, M.J., Pate, R.R. 2006. Validation and calibration of the Actical accelerometer in preschool children. Med Sci Sports Exerc 38(1): 152-157.

Pfeiffer, K.A., Dowda, M., McIver, K.L., Pate, R.R. 2009. Factors related to objectively measured physical activity in preschool children. Pediatr Exerc Sci 21: 196-208.

Straker, L., Campbell, A. 2012. Translation equations to compare ActiGraph GT3X and actical accelerometers activity counts. BMC Med Res Methodol 12:54. 
Timmons, B.W., Leblanc, A.G., Carson, V., Connor Gorber, S., Dillman, C., Janssen, I., et al. 2012. Systematic review of physical activity and health in the early years (aged 0-4 years). Appl Physiol Nutr Metab 37(4): 773-792.

Tremblay, M.S., Warburton, D.E., Janssen I, Paterson, D.H. Latimer, A.E. Rhodes, R.E., et al. 2011. 2011a. New Canadian physical activity guidelines. Appl Physiol Nutr Metab 36(1): 36$46 ; 47-58$.

Tremblay, M.S., Leblanc, A.G., Janssen, I., Kho, M.E., Hicks, A., Murumets, K., et al. 2011b. Canadian sedentary behavior guidelines for children and youth. Appl Physiol Nutr Metab 36: 59-64, 65-71.

Tremblay, M.S., Leblanc, A.G., Carson, V., Choquette, L., Connor Gorber, S., Dillman, C., et al. 2012a. Canadian physical activity guidelines for the early years (aged 0-4 years). Appl Physiol Nutr Metab 37(2): 345-369.

Tremblay, M.S., Leblanc, A., Carson, V., Choquette, L., Connor Gorber, S., Dillman C., et al. 2012b. Canadian sedentary behavior guidelines for the early years (aged 0-4 years). Appl Physiol Nutr Metab 37: 370-391.

Trost, S.G., Fees, B.S., Haar, S.J., Murray, A.D., Crowe, L.K. 2012. Identification and validity of accelerometer cut-points for toddlers. Obesity 20(11): 2317-2319.

Van Cauwenberghe, E., Gubbels, J., De Bourdeaudhuij, I., Cardon, G. 2011. Feasibility and validity of accelerometer measurements to assess physical activity in toddlers. Int J Behav Nutr Phys Act 8:67.

Wijtzes, A.I., Kooijman, M.N., Kiefte-de Jong, J.C., de Vries, S.I., Henrichs, J., Jansen, W., et al. 2013. Correlates of physical activity in 2-year-old toddlers: The generation R study. J Pediatr 163(3): 791-9.

Wong, S.L., Colley, R., Connor Gorber, S., Tremblay, M. 2011. Actical accelerometer sedentary activity thresholds for adults. J Phys Act Health 8(4): 587-591. 
World Health Organization. 2006. The WHO Child Growth Standards. Available from:

http://www.who.int/childgrowth/en/index.html. Accessed: January 15, 2015. 
Table 1. Descriptive characteristics of participants, by age group and sex

\begin{tabular}{|c|c|c|c|c|c|c|c|}
\hline \multirow[b]{3}{*}{ Characteristics } & \multirow[b]{3}{*}{ Total } & \multicolumn{6}{|c|}{ Age group } \\
\hline & & \multicolumn{2}{|c|}{$<18$ months } & \multicolumn{2}{|c|}{ 18-59 months } & \multicolumn{2}{|c|}{$\geq 60$ months } \\
\hline & & Boys & Girls & Boys & Girls & Boys & Girls \\
\hline Sample size, $\mathrm{n}$ & 90 & 13 & 15 & 18 & 27 & 12 & 5 \\
\hline Mean age, months & $\begin{array}{c}32.4 \\
(4.0-70.0)\end{array}$ & $\begin{array}{c}8.9 \\
(6.0-12.0)\end{array}$ & $\begin{array}{c}10.0 \\
(4.0-15.0)\end{array}$ & $\begin{array}{c}37.9 \\
(18.0-58.0)\end{array}$ & $\begin{array}{c}34.1 \\
(18.0-51.0)\end{array}$ & $\begin{array}{c}62.2 \\
(60.0-70.0)\end{array}$ & $\begin{array}{c}61.2 \\
(60.0-63.0)\end{array}$ \\
\hline Mean height, $\mathrm{cm}^{*}$ & $\begin{array}{c}90.8 \\
(62.0-117.2)\end{array}$ & $\begin{array}{c}73.0 \\
(65.0-79.4)\end{array}$ & $\begin{array}{c}72.0 \\
(62.0-83.0)\end{array}$ & $\begin{array}{c}95.5 \\
(78.0-114.0)\end{array}$ & $\begin{array}{c}93.6 \\
(75.5-116.5)\end{array}$ & $\begin{array}{c}111.1 \\
(102.7-117.2)\end{array}$ & $\begin{array}{c}111.8 \\
(108.0-115.4)\end{array}$ \\
\hline Mean weight, kg & $\begin{array}{c}13.4 \\
(5.9-23.0)\end{array}$ & $\begin{array}{c}9.2 \\
(7.3-12.9)\end{array}$ & $\begin{array}{c}8.2 \\
(5.9-10.2)\end{array}$ & $\begin{array}{c}15.0 \\
(9.3-21.7) \\
\end{array}$ & $\begin{array}{c}13.7 \\
(8.1-21.4)\end{array}$ & $\begin{array}{c}18.7 \\
(15.9-20.8) \\
\end{array}$ & $\begin{array}{c}20.1 \\
(16.9-23.0) \\
\end{array}$ \\
\hline Mean BMI, kg/m² & $\begin{array}{c}15.9 \\
(13.1-20.5)\end{array}$ & $\begin{array}{c}17.1 \\
(14.1-20.5)\end{array}$ & $\begin{array}{c}15.8 \\
(13.3-18.5)\end{array}$ & $\begin{array}{c}16.3 \\
(13.5-20.0)\end{array}$ & $\begin{array}{c}15.5 \\
(13.1-18.3)\end{array}$ & $\begin{array}{c}15.2 \\
(14.0-16.3)\end{array}$ & $\begin{array}{c}16.0 \\
(14.5-17.4)\end{array}$ \\
\hline Growth status, n (\%)** & & & & & & & \\
\hline Underweight & $3(3)$ & $1(8)$ & $1(7)$ & $1(6)$ & $0(0)$ & $0(0)$ & $0(0)$ \\
\hline Normal Weight & $83(92)$ & $10(77)$ & $14(93)$ & $16(89)$ & $27(100)$ & $12(100)$ & $4(80)$ \\
\hline Overweight & $4(4)$ & $2(15)$ & $0(0)$ & $1(6)$ & $0(0)$ & $0(0)$ & $1(20)$ \\
\hline $\begin{array}{l}\text { Mean number of valid } \\
\text { days of accelerometry }\end{array}$ & $\begin{array}{c}6.1 \\
(4.0-7.0)\end{array}$ & $\begin{array}{c}5.7 \\
(4.0-7.0) \\
\end{array}$ & $\begin{array}{c}5.9 \\
(4.0-7.0)\end{array}$ & $\begin{array}{c}6.1 \\
(4.0-7.0)\end{array}$ & $\begin{array}{c}6.2 \\
(5.0-7.0)\end{array}$ & $\begin{array}{c}6.3 \\
(4.0-7.0)\end{array}$ & $\begin{array}{c}6.2 \\
(6.0-7.0)\end{array}$ \\
\hline $\begin{array}{l}\text { Mean wear time per day } \\
\text { in hours*** }\end{array}$ & $\begin{array}{c}10.2 \\
(7.7-12.0)\end{array}$ & $\begin{array}{c}9.0 \\
(7.9-10.6)\end{array}$ & $\begin{array}{c}9.4 \\
(7.7-10.6)\end{array}$ & $\begin{array}{c}10.5 \\
(8.6-11.8)\end{array}$ & $\begin{array}{c}10.4 \\
(8.7-12.0)\end{array}$ & $\begin{array}{c}11.2 \\
(9.6-12.0)\end{array}$ & $\begin{array}{c}11.5 \\
(11.0-11.8)\end{array}$ \\
\hline
\end{tabular}

Values are presented as means (range) *Mean length for children under 2 years of age**For growth status, percentile was first determined using weight-for-length for children under 2 years of age and BMI-for-age for children 2 years of age and older. Children aged 0 to 5 years were characterized as underweight if in the $<3^{\text {rd }}$ centile and overweight if in the $>97^{\text {th }}$ centile. Children 5 years and older were characterized as underweight if in the $<3^{\text {rd }}$ centile and overweight if in the $>85^{\text {th }}$ centile.

Proportion of children overweight or obese is defined as BMI-for-age $>97^{\text {th }}$ percentile $* * *$ Wear time between 8:00am and 8:00pm 
Table 2. Average daily minutes of activity at various levels of movement intensity, by age group and sex

\begin{tabular}{|c|c|c|c|c|c|c|c|c|}
\hline \multirow{3}{*}{ Sex / Age group } & \multicolumn{8}{|c|}{ Intensity of activity, average minutes per day } \\
\hline & \multicolumn{2}{|c|}{ Sedentary } & \multicolumn{2}{|c|}{ Light } & \multicolumn{2}{|c|}{$\begin{array}{c}\text { Moderate- } \\
\text { to-vigorous }\end{array}$} & \multicolumn{2}{|c|}{ Total } \\
\hline & $\min / \mathrm{d}$ & $95 \% \mathrm{CI}$ & $\min / \mathbf{d}$ & $95 \% \mathrm{CI}$ & $\min / \mathrm{d}$ & $95 \% \mathrm{CI}$ & $\min / \mathbf{d}$ & $95 \% \mathrm{CI}$ \\
\hline All participants & 407 & $396-418$ & 179 & $166-193$ & 27 & $21-33$ & 206 & $189-223$ \\
\hline$<18$ months & 435 & $413-456$ & 114 & $90-138$ & 4 & $3-6$ & 118 & $94-142$ \\
\hline 18-59 months & 395 & $381-409$ & 203 & $192-214$ & $29^{*}$ & $23-36$ & $232 *$ & $218-246$ \\
\hline$\geq 60$ months & 396 & $371-421$ & 224 & $203-244$ & $58^{*}$ & $44-72$ & $282 *$ & $252-312$ \\
\hline Boys & 407 & $392-422$ & 179 & $157-200$ & 29 & $21-37$ & 208 & $180-235$ \\
\hline$<18$ months & 444 & $417-471$ & 94 & $63-126$ & 3 & $2-5$ & 97 & $66-129$ \\
\hline $18-59$ months & 393 & $371-415$ & 206 & $191-222$ & 30 & $19-42$ & 236 & $218-255$ \\
\hline$\geq 60$ months & 389 & $363-416$ & 229 & $202-256$ & 54 & $40-69$ & 283 & $247-319$ \\
\hline Girls & 408 & $391-424$ & 180 & $162-197$ & 25 & $17-33$ & 205 & $183-227$ \\
\hline$<18$ months & 427 & $392-462$ & 131 & $94-168$ & 5 & $2-8$ & 136 & $100-173$ \\
\hline $18-59$ months & 396 & $377-415$ & 201 & $185-217$ & 29 & $20-38$ & 230 & $209-250$ \\
\hline$\geq 60$ months & 413 & $331-495$ & 211 & $172-250$ & 68 & $22-114$ & 279 & $194-363$ \\
\hline
\end{tabular}

*Significantly more active than children in the $<18$ month age group $(\mathrm{p}<0.001)$. 
Table 3. A comparison of the TARGet Kids! and CHMS cohorts for mean daily minutes of sedentary time and total, light and moderate-to-vigorous physical activity and proportion of children meeting the guidelines by age group

\begin{tabular}{|c|c|c|c|c|c|c|}
\hline Age & Study & $\begin{array}{c}\text { Sedentary time } \\
\min / \mathbf{d} \\
\left(95 \% \mathrm{CI}^{*}\right)\end{array}$ & $\begin{array}{c}\text { LPA } \\
\mathrm{min} / \mathrm{d} \\
(95 \% \mathrm{CI})\end{array}$ & $\begin{array}{c}\text { MVPA } \\
\text { min/d } \\
(95 \% \mathrm{CI})\end{array}$ & $\begin{array}{c}\text { Total PA } \\
\text { min/d } \\
(95 \% \text { CI })\end{array}$ & $\begin{array}{l}\text { Proportion meeting } \\
\text { guidelines*** } \\
(95 \% \mathrm{CI})\end{array}$ \\
\hline \multirow[t]{2}{*}{$\begin{array}{l}36-59 \\
\text { months }\end{array}$} & TARGet Kids! & $\begin{array}{c}407 \\
(389-426)\end{array}$ & $\begin{array}{c}202 \\
(189-215)\end{array}$ & $\begin{array}{c}43 \\
(35-50)\end{array}$ & $\begin{array}{c}245 \\
(229-261)\end{array}$ & $\begin{array}{c}83.8 \% \\
(75.4-92.3)\end{array}$ \\
\hline & CHMS & $\begin{array}{c}348 \\
(332-365)\end{array}$ & $\begin{array}{c}285 \\
(275-296) \\
\end{array}$ & $\begin{array}{c}66 \\
(61-72) \\
\end{array}$ & $\begin{array}{c}352 \\
(340-364) \\
\end{array}$ & $\begin{array}{c}83.8 \% \\
(77.7-90.0) \\
\end{array}$ \\
\hline \multirow[t]{2}{*}{$\begin{array}{l}\geq 60 \\
\text { months }\end{array}$} & TARGet Kids! & $\begin{array}{c}396 \\
(371-421)\end{array}$ & $\begin{array}{c}224 \\
(203-244)\end{array}$ & $\begin{array}{c}58 \\
(44-72)\end{array}$ & $\begin{array}{c}282 \\
(252-312)\end{array}$ & $\begin{array}{c}12.6 \% \\
(1.2-24.1)\end{array}$ \\
\hline & CHMS & $\begin{array}{c}381 \\
(361-400)\end{array}$ & $\begin{array}{c}275 \\
(261-289)\end{array}$ & $\begin{array}{c}68 \\
(62-74)\end{array}$ & $\begin{array}{c}343 \\
(325-361)\end{array}$ & $\begin{array}{c}13.7 \% \\
(9.4-18.0)\end{array}$ \\
\hline
\end{tabular}

*CI, Confidence Interval

**For children 36-59 months, the proportion meeting $180 \mathrm{~min} / \mathrm{d}$ of total PA on at least 4 days; for children $\geq 60$, the proportion meeting $60 \mathrm{~min} / \mathrm{d}$ of MVPA on at least 6 days 
Figure 1. Proportion of children meeting the Canadian physical activity guidelines by age group 


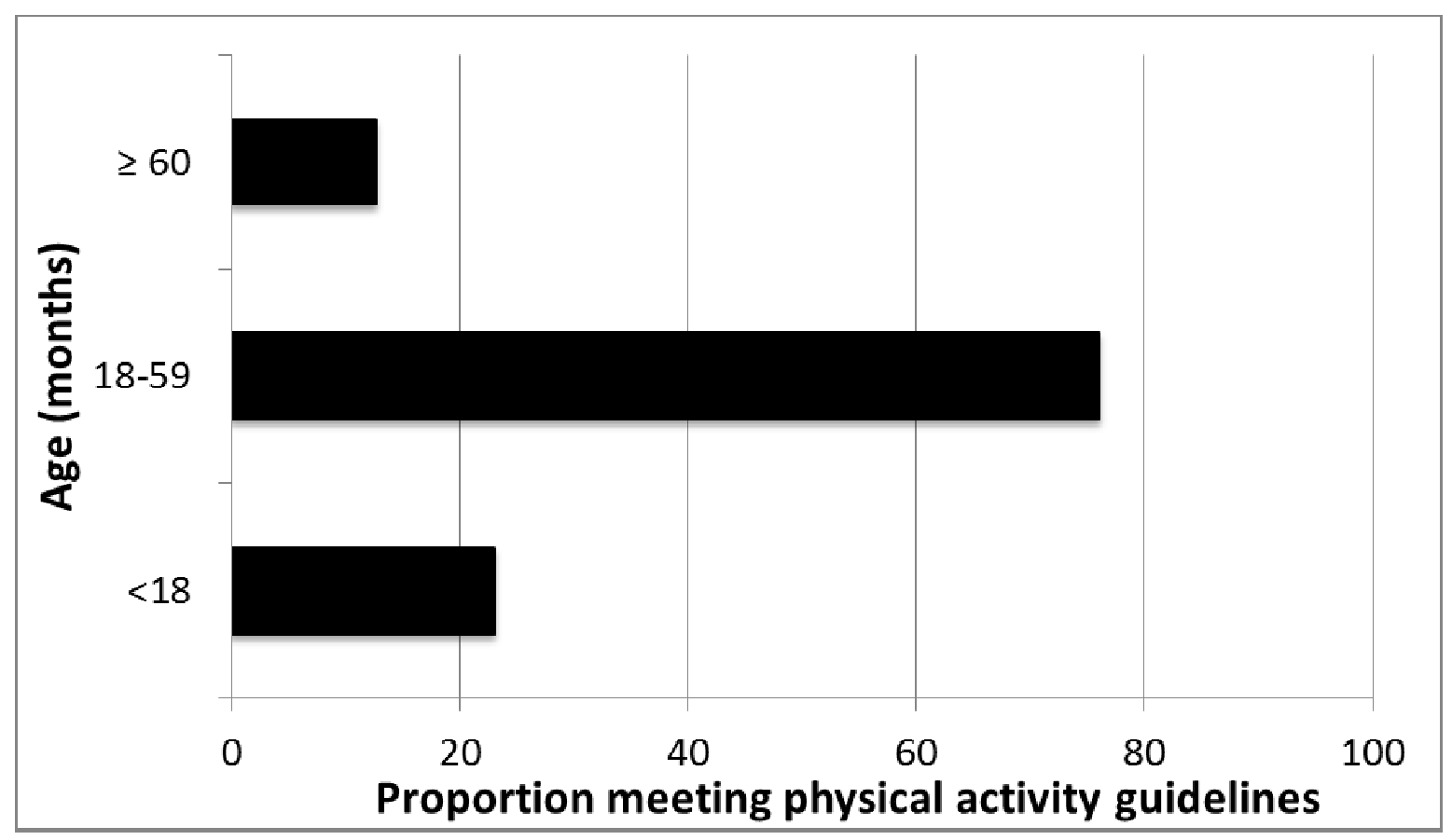

